\title{
Da Helena grega à Helena fluminense: Machado de Assis e a tradição clássica
}

\section{From the Greek Helen to the "Fluminense" Helen: Machado de Assis and the classical tradition}

Edson Ferreira Martins

Universidade Federal de Viçosa (UFV), Viçosa / Brasil.

eferreiramartins@hotmail.com

Resumo: No presente trabalho, por meio da releitura de elementos da cultura greco-romana inseridos por Machado de Assis em seu romance Helena, pretende-se discutir a recepção da cultura clássica no projeto literário machadiano, indagando-se sobre as funções a que se presta a incorporação dessa camada intertextual (BAKHTIN, 2002) nos escritos do romancista brasileiro, a par do que preconizava o próprio Machado na persona de um outro eu: a do crítico literário, atento às transformações sociais e estéticas do Brasil oitocentista. Desse processo, resulta a utilização sistemática das citações de elementos da cultura clássica para a caracterização psicológica da sua Helena, a partir da técnica da emulação operacionalizada por meio da reescrita de mitos relativos às personagens gregas Penélope e Helena de Esparta.

Palavras-chave: cultura clássica; emulação; recepção; dialogismo; mito; Machado de Assis.

Abstract: Through multiple readings of elements from the Greco-Roman culture inserted by Machado de Assis in his novel Helena, this study intends to discuss the reception of classical culture in the Machadian literary project, investigating the function that the incorporation of this intertextual layer (BAKHTIN, 2002) has on the writings of the Brazilian 
novelist, considering what Machado himself proposed through the persona of another self: the literary critic, aware to the social and aesthetic transformations of nineteenth-century Brazil. From this process results the systemic use of references to elements from the classical culture to build the psychological portrayal of his Helena, based on the emulation technique effected through the rewriting of myths related to the Greek characters of Penelope and Helen of Sparta.

Keywords: classical culture; emulation; reception; dialogism; myth; Machado de Assis.

Recebido em 23 de maio de 2016.

Aprovado em 2 de agosto de 2016.

\section{A reescrita dos clássicos greco-latinos no romance machadiano}

Para a compreensão da reescrita que Machado promove dos clássicos greco-romanos, é fundamental recorrermos ao conceito de dialogismo, utilizado por Mikhail Bakhtin (2002), particularmente no capítulo "O discurso em Dostoiévski", quando o teórico russo promove uma subcategorização dos tipos de discurso que ele encontra na prosa dostoievskiana. Ao refletir sobre eles, principia por distinguir o discurso monológico do discurso dialógico. O primeiro é definido como sendo o tipo de discurso que não oferece espaço para uma réplica; ainda que apresentando dois juízos com uma relação lógica entre si, tal relação não se configura como dialógica. Já no discurso dialógico, continua Bakhtin (2002), dois juízos convergem sobre um mesmo objeto, um mesmo tema, transpassando, assim, discursos de outrem e possibilitando que um juízo expresse uma posição, um comentário sobre o outro, de maneira que ocorra uma interação entre eles. Há que se levar em conta, portanto, que a noção de dialogismo bakhtiniana amplia esse conceito para além da mera interação entre enunciados de indivíduos distintos; para o crítico russo, qualquer enunciado carrega em si outros enunciados, que o perpassam dialogicamente. O resultado dessa noção dialógica de linguagem é a produção de enunciados marcados por vozes polifônicas, quando o autor defende a posição de que não existe um discurso adâmico, puro: um membro de um grupo falante nunca encontra previamente a palavra 
como uma palavra neutra na língua, isenta das aspirações e avaliações de outros ou despovoada das vozes dos outros. Donde conclui que o discurso monológico é inexistente nos enunciados de um indivíduo.

A produção dos romances machadianos apresenta inúmeros exemplos de apropriações de discursos alheios, sendo seus textos perpassados por múltiplas vozes, que, sob o crivo do narrador, são utilizadas para a manifestação dos discursos da paródia e da estilização. Como observa o próprio Bakhtin (2002, p. 160), "as relações dialógicas são possíveis também com sua própria enunciação como um todo, com partes isoladas deste e com uma palavra isolada nele". Conforme demonstraremos adiante, Machado fará largo uso do recurso da referência às "partes isoladas" dessas enunciações, de que fala Bakhtin, ao lançar mão, de forma recorrente, do processo citacional em suas criações ficcionais, como é o caso do romance Helena.

\section{Uma jovem um pouco parecida com Penélope}

Helena, publicado em 1876, como se sabe, não é o romance de estreia de Machado de Assis, mas sim sua terceira incursão no gênero. Para uma leitura mais atenta da relação entre mitos gregos e a construção de suas heroínas, é preciso observar que, nos romances anteriores Ressurreição (1872) e A mão e a luva (1874) -, se tivermos em mente Helena, Machado vai buscar a comparação de Lívia e Guiomar, as respectivas heroínas de tais romances, com outras referências do mundo clássico antigo: "um modelo de graça antiga", qual uma "estátua antiga" (ASSIS, 2006b, p. 130), no caso da primeira; deusas de beleza física (Vênus e Diana), no caso da segunda. ${ }^{1}$ Nesse sentido, uma análise contrastiva dos três romances quanto a esse aspecto apresenta uma pergunta fundamental, dado que Machado, no terceiro romance, ao mesmo tempo em que continuará ininterruptamente a estilizar fontes gregas antigas, recorrerá a outros personagens para a composição das características da sua Helena e do enredo do romance: por que valer-se

\footnotetext{
${ }^{1}$ Quanto à recepção dos clássicos no romance Ressurreição, o relatório da pesquisa que temos em curso foi concluído em julho de 2016. Sobre a utilização do mito de Vênus para a composição psicológica do caráter de Guiomar em A mão e a luva, veja-se o trabalho de MARTINS, 2015.
} 
particularmente de Penélope e Helena como pontos de convergência dessas relações dialógicas, neste caso?

A primeira citação no texto que remete à reescrita dos mitos gregos dá-se pela referência à esposa do astuto herói grego Ulisses, Penélope:

Durante dois dias não saiu ele de casa. Tendo recebido alguns livros novos, gastou parte do tempo em os folhear, ler alguma página, colocá-los nas estantes, alterando a ordem e a disposição dos anteriores, com a prolixidade e o amor do bibliófilo. Helena ajudava-o nesse trabalho, - um pouco parecido com o de Penélope, - porque a ordem estabelecida ao meio-dia era às vezes alterada às duas horas, e restaurada na seguinte manhã. Estácio, entretanto, não ficava todo entregue aos livros; admirava a solicitude da irmã, a ordem e o cuidado com que ela o auxiliava. Helena parecia não andar; o vulto resvalava silenciosamente, de um lado para outro, obedecendo às indicações do irmão, ou pondo em experiência uma ideia sua. Estácio parava às vezes, fatigado; ela continuava imperturbavelmente o serviço. Se ele lhe fazia algum reparo, a moça respondia erguendo os ombros ou sorrindo, e prosseguia. Então Estácio segurava-lhe nos pulsos e exclamava rindo:

- Sossega, borboleta!

Helena parava, mas eram só poucos minutos; volvia logo ao trabalho com a mesma serena agitação. Era assim que as horas se passavam na intimidade mais doce, e que a recíproca afeição ia excluindo toda a preocupação alheia; era assim que a influência de Helena assumia as proporções de voto preponderante (ASSIS, 2006b, p. 304-305).

Nesse ponto da narrativa, Helena já mora na casa da família do falecido Conselheiro Vale, que tinha manifestado seu desejo final, em testamento, de que ela fosse reconhecida como sua filha legítima e inserida na casa da nobre família fluminense onde habitavam sua irmã, D. Úrsula, uma senhora que "contava [...] cinquenta e poucos anos; era solteira; vivera sempre com o irmão, cuja casa dirigia desde o falecimento da cunhada" (ASSIS, 2006b, p. 273) e que "era eminentemente severa a respeito dos costumes" (ASSIS, 2006b, p. 278), além do sobrinho desta e filho do conselheiro, Estácio, que tinha então "vinte e sete anos, e era formado em matemáticas” (ASSIS, 2006b, p. 273). Aponta, ainda, o 
narrador machadiano, que o jovem herdara da mãe o gênio sentimental e os toques de orgulho. A partir dessa novidade grandiosa, da paternidade assumida de Helena pelo Conselheiro Vale, a narrativa se desenvolve com o foco na relação da heroína com seu irmão Estácio, que vão desenvolvendo afinidades ao se conhecerem, sem terem tido a inocência da infância comum.

Se pensarmos no texto literário como um mosaico de citações, como quer Bakhtin (2002), a cena descrita por Machado no trecho transcrito acima remete o leitor à narrativa épica da Odisseia, na qual temos o relato da tessitura de uma mortalha, que Penélope teve a ideia de preparar como presente ao sogro Laertes. Em diversas passagens da epopeia homérica, o episódio é relembrado na perspectiva de diferentes personagens: Antínoo, por exemplo, em uma assembleia em Ítaca, conta aos presentes a história, a fim de justificar a usurpação desenfreada que os pretendentes promoviam dilapidando os bens de Ulisses; os mesmos pretendentes também confirmam o relato, respondendo à Agamêmnon no Hades, quando perguntados quem eram e como chegaram todos de uma vez à terra dos mortos, esmagados pelo errante rei de Ítaca, auxiliado por seu filho Telêmaco e alguns criados; ou ainda pela própria Penélope, que assim fala no poema:

Urgem-me os procos, e eu maquino enganos.

Um gênio me inspirou tramar imensa

Larga teia delgada, e assim lhes disse:

- Amantes meus depois de morto Ulisses,

Vós não me insteis, o meu lavor perdendo,

sem que do herói Laertes a mortalha

Toda seja tecida, para quando

No sono longo o sopitar o fado:

Nenhuma Argiva exprobre-me um funéreo

Manto rico não ter quem teve tanto. -

A diurna obra desfazia à noite,

E os entretive ilusos por três anos (HOMERO, 2009b, XIX, 104-116). ${ }^{2}$

${ }^{2}$ Numeração correspondente a livro e versos, respectivamente. 
O episódio em questão está ligado à estratégia de que a esposa de Ulisses astuciosamente lançou mão com o intuito velado de, na verdade, retardar um novo casamento com qualquer dos pretendentes - que insistiam em matar Ulisses antes da hora sob a alegação de que, uma vez que os combatentes da guerra de Troia já haviam retornado aos seus respectivos lares e apenas Ulisses ainda não o fizera, ele só poderia ter perecido nos mares por obra de algum deus ou pelas mãos de algum povo selvagem.

Partindo-se da ideia de que um texto se constrói a partir do diálogo com outros textos, acreditamos que Machado estilize o episódio em particular conforme a versão homérica, fazendo questão de dar ênfase à expressão entre travessões "- um pouco parecido com o de Penélope -", que busca orientar o leitor sobre o modo como agia Helena em relação a Estácio na casa recém-adentrada por ela: assim como Penélope, que tecia e destecia a mortalha, pensando no amor de Ulisses, Helena arrumava e desarrumava os livros, fruindo da primeira afeição daquele homem que o destino dava-lhe socialmente como irmão. Embora as relações entre os pares sejam de natureza diversa - esposo/esposa versus irmão/irmã -, o narrador machadiano aproveita-se da reescrita do mito grego para salientar que Helena é tão ardilosa quanto Penélope, ao mesmo tempo em que sugere um propósito semelhante de ambas as personagens femininas: não se distanciar de quem se ama - no caso de Penélope, um novo matrimônio cavaria um abismo insuperável entre ela e Ulisses, fazendo com que a imagem do homem amado desaparecesse por completo; no de Helena, o gesto inaugurava uma aproximação típica do despertar da paixão, de onde vem aquela "serena agitação" que revolvia seu coração ao compartilhar a "intimidade mais doce" ao lado de Estácio, com quem cultiva gradativamente a "recíproca afeição" que excluía "toda a preocupação alheia".

Adentrado o espaço da casa, podemos notar que há uma obediência programática da Helena machadiana no trato com Estácio, cujo modus operandi se realiza sob o signo ambíguo do respeito casado à dedicação - não por acaso, são essas também as características mais destacadas da esposa de Ulisses, na tradição de seu mito. No romance, o narrador afirma que "o vulto" da jovem "resvalava silenciosamente" ao andar pela sala, mantendo, assim, a personagem opaca, que objetiva não fazer frente ao irmão, mas antes busca aceitar com resignação o que lhe é posto, "obedecendo às indicações" ou dizendo não poder decidir nada 
sozinha, pois, segundo a heroína, "minha vontade tem um limite, que é a sua [a de Estácio]" (ASSIS, 2006b, p. 343). Essa obediência, como bem nos mostra o narrador ao longo dos primeiros capítulos, fará com que a dita irmã de Estácio conquiste espaço na casa e no coração dele e de D. Úrsula, podendo a jovem pôr "em experiência uma idéia sua" (ASSIS, 2006b, p. 305), chegando mais adiante a assumir as proporções de voto preponderante. Segundo o narrador, "Helena [...] se tornara a verdadeira dona de casa, a diretora ouvida e obedecida" (ASSIS, 2006b, p. 310). Cada vez mais, Helena vai se construindo, para o leitor, um pouco parecida com Penélope, guardadas as grandes diferenças de casta entre as personagens: enquanto uma era rainha conhecida e respeitada, a origem da outra "continuava misteriosa; vantagem grande, porque o obscuro favorecia a lenda" (ASSIS, 2006b, p. 288) - dirá, em tom metaficcional, o narrador machadiano.

\section{Da Helena grega à Helena fluminense}

Indo além da citação explícita de Penélope, a escolha do nome da personagem principal não poderia ser melhor pensada por um romancista que desejava estabelecer uma poética da emulação com as matrizes antigas da tradição literária ocidental. Em sua gênese, a homônima da heroína machadiana é aquela por quem - segundo as origens da literatura grega - milhares de homens desceram ao Hades, perecendo por vontade da implacável Moira no interminável cerco grego à cidadela de Troia, a fim de resgatar a esposa de Menelau, raptada pelo sedutor príncipe troiano Páris. No que se refere à lenda de Helena, avaliando a recepção do épico no trágico antigo, Grimal (2005) aponta a complexidade dos mitos que envolviam essa personagem. Observa o estudioso que, na versão de Eurípedes, ao voltar de Troia, antes de regressar definitivamente a Esparta, o casal Helena-Menelau vai visitar Agamêmnon em Argos, precisamente no dia em que Orestes tinha matado Clitemnestra e Egisto, assassinos do irmão de Menelau. Ao ver Helena, descrita na peça do tragediógrafo com fasto oriental à moda troiana, Orestes, tomado pela cólera e julgando-a responsável por todos os infortúnios sofridos por sua família, tenta matá-la:

[...] Por ordem de Zeus, porém, Apolo raptou-a e tornou-a imortal. Esta lenda não está conforme à tradição mais corrente que, após a Odisseia, mostra Helena regressando a Esparta juntamente com Menelau e sendo exemplo de todas as virtudes domésticas. 
No entanto, a lenda da divinização de Helena conservava alguma autoridade, uma vez que se conhecia grande número de santuários a ela consagrados, nos quais se honrava também Menelau. Este teria sido divinizado a pedido de Helena, que pretendia dar-lhe alguma compensação dos tormentos que lhe infligira em vida (GRIMAL, 2005, p. 199-200).

Na composição da protagonista de seu romance, em um primeiro momento, Machado se valeu de Penélope para dar um tom mais perseverante e dedicado ao seu caráter; de outra parte, o romancista brasileiro recorrerá à Helena espartana para evocar particularmente ecos do trágico que pretendia estilizar. ${ }^{3}$ A relação entre as duas Helenas, portanto, vai além da simples confluência do nome, como pretendemos demonstrar. Comecemos, então, a traçar esses pontos de convergência entre as personagens.

\footnotetext{
${ }^{3}$ No que tange ao diálogo com as literaturas clássicas, há ainda no romance uma alusão a outro texto que põe em cena outra personagem trágica - Dido, a rainha cartaginesa -, numa passagem em que Machado, por meio de uma intertextualidade implícita, estiliza o texto virgiliano, a nosso ver com interesse em realçar os aspectos trágicos que circundam o destino da personagem Helena. Eis o trecho em questão, excerto da Eneida, no qual o mantuano canta o episódio dos malfadados amores de Eneias e Dido: "Com grande estrondo de súbito o céu principia a embrulhar-se,/ logo seguido de um forte aguaceiro e de infindo granizo./ A comitiva dos tírios e os moços esbeltos de Troia,/ bem como o neto de Vênus, transidos de medo, nos campos/ se dispersaram. Ribeiras despencam das altas montanhas./ Dido e o caudilho troiano se acolhem à mesma caverna. [...]/ Esse, o primeiro dos dias letais, o princípio de todas as desventuras de Dido" (VIRGÍliO, 2005, IV, 160-170). Em seu romance, por sua vez, Machado assim se expressa: "Insistindo Helena, prometeu ele que nessa tarde iria visitar Camargo. De tarde desabou um temporal violento. A força do vento e da trovoada abrandou; mas a chuva continuou a cair com a mesma violência; era impossível ir ao Rio Comprido. Estácio estimou aquele obstáculo; era melhor adorar de longe a imagem da moça do que ir colher algum desgosto junto a ela. De pé, encostado a uma das vidraças da sala de visitas, via cair as grossas toalhas de água. Ao lado estava sentada Helena, não alegre, mas taciturna e melancólica. - É tão bom ver chover quando estamos abrigados! exclamou ele. Tenho lá na estante um poeta latino que diz alguma coisa neste sentido... Que tem você?" (ASSIS, 2006b, p. 308). Agradecemos à Professora Charlene Martins Miotti, que nos chamou atenção para a possível reminiscência do texto virgiliano na reescrita operada por Machado a partir desse referido "poeta latino".
} 
Segundo Grimal (2005), na cultura grega, a personagem Helena, citada por Homero, entre outras fontes arcaicas, era filha de Zeus e Leda, mas seu pai humano era Tíndaro. Note-se que a personagem machadiana homônima possuía como mãe Ângela, e também dois pais, o Conselheiro Vale e Salvador; analisando-se a transposição das lendas gregas para o texto machadiano, do épico ao romance temos a conversão do grandioso Zeus na figura socialmente influente do conselheiro, ao passo que o herói espartano Tíndaro teria o seu duplo no humilde pai biológico de Helena, ironicamente denominado Salvador. No tocante às repentinas mudanças na vida social, observe-se que uma não foi bemaceita em Troia, enfrentando desconfianças e dificuldades de adaptação, sentimentos compartilhados pela outra, que também sofre ao ser colocada no seio da aristocrática família dos Vale, tendo sua presença contestada por alguns membros que frequentavam aquele nicho burguês, o que pode ser atestado, respectivamente, nos trechos a seguir:

\author{
À torre vendo aproximar-se Helena, \\ Dizem baixo entre si: \\ "Não sem motivo \\ Povos rivais aturam tantos males! \\ Que porte e garbo! efígie é das deidades. \\ Mas, tal qual seja, embarque; a nós exício \\ Não continue a ser e a nossos filhos" (HOMERO, 2009, \\ III, 133-139).
}

As pessoas da intimidade da casa acolheram Helena com a mesma hesitação de D. Úrsula. Helena sentiu-lhes a polidez fria e parcimoniosa. Longe de abater-se ou vituperar os sentimentos sociais, explicava-os e tratava de os torcer em seu favor, - tarefa em que se esmerou superando os obstáculos na família; o resto viria de si mesmo (ASSIS, 2006b, p. 286-287).

A beleza física inigualável da Helena grega será estilizada também no diálogo intertextual que Machado estabelece com a tradição da Antiguidade. Se a personagem homérica era "então a mulher mais bela do mundo e exemplo de todas as virtudes domésticas" (GRIMAL, 2005, p. 198), a machadiana, por sua vez, 
Era dócil, afável, inteligente. Não eram estes, contudo, nem ainda a beleza, os seus dotes por excelência eficazes. $\mathrm{O}$ que a tornava superior e lhe dava probabilidade de triunfo, era a arte de acomodar-se às circunstâncias do momento e a toda a casta de espíritos, arte preciosa, que faz hábeis os homens e estimáveis as mulheres. Helena praticava de livros ou de alfinetes, de bailes ou de arranjos de casa, com igual interesse e gosto, frívola com os frívolos, graves com os que o eram, atenciosa e ouvida, sem entono nem vulgaridade. Havia nela a jovialidade da menina e a compostura da mulher feita, um acordo de virtudes domésticas e maneiras elegantes (ASSIS, 2006b, p. 286).

Essas "virtudes domésticas e maneiras elegantes", que conviviam harmoniosamente em Helena só tinham sentido em uma sociedade cuja moral valorizasse um modo de viver cortês, exatamente o meio social descrito pelos romances de Machado, ambientados no Rio de Janeiro urbano do oitocentos. Nesse ponto, nos parece que o Bruxo irá adaptar mais um fragmento do mito da Helena espartana à composição da sua. Como já salientamos, a Helena grega foi o motivo de uma das maiores guerras da Antiguidade Clássica, a guerra de Troia, que, conforme salienta Brandão (2012), tem sua gênese em um juramento feito entre os pretendentes da belíssima moça de defender a honra do escolhido por ela:

Quando uma verdadeira multidão de pretendentes à mão de Helena assediava a princesa, Tíndaro, a conselho do solerte Ulisses, ligou-os por dois juramentos: respeitar a decisão de Helena na escolha do noivo, sem contestar a posse da jovem esposa e se o escolhido fosse, de qualquer forma, atacado, os demais deviam socorrê-lo (BRANDÃO, 2012, p. 90).

Ora, assim como o pacto selado entre os pretendentes à mão da mais bela mulher da Hélade, o qual garantia a segurança do escolhido como esposo pela princesa, o testamento deixado pelo Conselheiro Vale traria a mesma sensação de segurança econômica e moral ao futuro marido da jovem e muito bela Helena - alçada socialmente à condição de princesa após esse fato jurídico. Tal pacto, entretanto, fora dos contornos aristocráticos do mundo grego arcaico, se dá nos termos da complexa rede socioeconômica do Brasil do Segundo Reinado, segundo os quais o conselheiro dita as normas aos demais membros de sua família. Nesses 
termos, na figura do pater familias, decide ele unilateralmente pela proteção de Helena e - por que não o dizer? - indiretamente também de seu futuro "escolhido", garantia das credenciais que o nome Vale possuía (mais uma vez a onomástica machadiana fala por si), dada a herança material que a jovem asseguraria com a adoção oficializada.

Dando sequência à reescrita dos mitos gregos em seu romance, Machado se reportará ao episódio do rapto da Helena espartana. A tradição mítica, em sua versão mais conhecida, entrecruza a história da seguinte maneira: quando Afrodite garantiu a Páris o amor da mais bela mulher do mundo, após este declará-la possuidora da maior beleza entre as deusas presentes no casamento de Peleu e Tétis, o príncipe troiano estava desde então destinado ao amor da esposa de Menelau. Segundo Brandão (2012, p. 113), "da cidadela de Ílion, em companhia de Eneias, partiu Alexandre para Esparta, em busca de Helena”. Aí foi recebido por Menelau, mas o rei de Esparta precisou viajar a fim de prestar homenagens a um parente falecido; em seguida, entregou os hóspedes aos cuidados da esposa, que, apaixonada, reuniu todos os tesouros que pôde e fugiu com Páris, deixando em Esparta sua filha Hermíone, ainda uma criança:

Quando o príncipe Páris ou Alexandre raptou Helena, Menelau, a quem ela escolhera por marido, pediu auxílio a seu irmão Agamêmnon, o poderoso rei de Micenas, que também estava ligado a Menelau por juramento. Agamêmnon foi escolhido comandante supremo da armada aqueia, seja por seu valor pessoal, seja porque era uma espécie de rei suserano, dada a importância de Micenas no conjunto do mundo aqueu, quer por efeito de hábil campanha política. Convocados os demais reis ligados por juramento a Menelau, formou-se o núcleo da grande armada destinada a vingar o rapto de Helena e atacar Troia, para onde Páris levara a princesa (BRANDÃO, 2012, p. 90-91).

No encadeamento dos mitos relativos à guerra de Troia, a carga de tragicidade da história entre gregos e troianos começa com o gesto inaugural do rapto de Helena, prometida a Páris por Afrodite. Esse episódio em particular - o gesto do rapto -, conforme dele falam diferentes versões dos mitos gregos antigos em torno da personagem, vai ser revisitado por Machado em dois momentos particulares de seu romance. 
No primeiro deles, temos não um rapto em si, mas o seu planejamento. Mendonça, amigo de Estácio que estava enamorado de Helena, pondera as (des)vantagens de pedir ou não sua mão, pois "dever a esposa à evocação do nome do conselheiro equivalia a um rapto" (ASSIS, 2006b, p. 349). Machado se vale do mesmo substantivo, "rapto", abstratizando, porém, em seu romance o que era concreto no mito antigo, dado que Mendonça tem receio de raptar o sobrenome, e não propriamente Helena. Em termos socioeconômicos, observe-se aqui a alusão de Machado ao tema do casamento de interesse, ao qual o autor já havia dedicado o romance anterior, A mão e a luva. Mais à frente, no mesmo capítulo, Estácio, em conversa com a irmã, tratando da decisão de ela casar-se ou não com Mendonça, indaga em tom de ciúme: "a tua felicidade exige que esse homem venha cá, que te cases com ele, que nos fujas?" (ASSIS, 2006b, p. 350). Pela estilização dos mitos gregos, tanto a ideia do rapto quanto a da fuga permeiam a expectativa do leitor nesse ponto do romance, a partir das artimanhas criadas pelo narrador. Machado, contudo, inverterá a lógica de ação da sua Helena em contraste com a espartana ao apresentar o desenlace da história: a Helena machadiana não só não foge com um amante, como não se casa com ninguém, ainda que confesse que ama a um certo homem; além disso, revelado o segredo de sua paternidade, sua origem humilde, tudo corroborará para o desencadeamento de sua tragédia pessoal, envolvida pela vergonha da suspeita alheia sobre seus reais interesses junto à família Vale, o que culminará em sua depressão e, finalmente, em sua morte. No diálogo intertextual, não há só presenças, mas também estratégias de silenciamento: o romancista afasta-se aqui de alguns episódios fundamentais da história da Helena espartana, que foge, se casa, usurpa alguns bens e desencadeia uma série de tragédias. Machado, portanto, subverte em parte o sentido do mito grego, propondo o desfecho em outra direção: o do sufocamento moral e subsequente morte da inocente Helena por uma sociedade patriarcal, que encontra agentes determinados a impedir a ascensão social dos membros das camadas menos abastadas, tal como agem dentro do romance a fria D. Úrsula, o amargo Dr. Camargo, para o que não deixa de corroborar o espírito do indeciso Estácio.

O topos do rapto de Helena não termina ainda, retornando páginas adiante, quando aparece na narrativa o pai biológico de Helena, elevando 
ao grau máximo a carga dramática do romance. ${ }^{4}$ Em dois capítulos construídos, praticamente na totalidade, em estrutura de diálogos (os de número XXV e XXVI), Salvador, ao ter de explicar-se perante o Padre Melchior e Estácio sobre a natureza de sua "relação" com Helena, trará à tona as verdades trágicas que envolvem os episódios relativos à infância de sua filha legítima; confessa, inclusive, que não estava ausente de seu espírito até mesmo "empregar a violência", se preciso, para raptar a própria filha, após descobrir-se traído e abandonado pela mulher, como confessa a seus desconfiados interlocutores, no desvendar de um dos mistérios sobre os quais Machado constrói a trama:

Dois dias depois da carta de Ângela, escrevi-lhe pedindo meia hora de conversação; nada mais. Ângela concedeume a entrevista. Meu plano era arrebatar-lhe Helena; ela parece que o previu, recebendo-me sozinha, no jardim, às nove horas da noite. [...] "Meu fim, declarei eu, é só um: levar Helena; Helena é minha filha, não quero deixá-la entregue a seus maus exemplos." [...] Cedi aparentemente. Minha resolução estava assentada [...].

- Segundo rapto, observou o padre. O senhor condenava-se a só adquirir vislumbre de felicidade por meios violentos. - Tem razão, respondeu Salvador com tristeza; um abismo chamava outro abismo. Felizes os que sabem o caminho reto da vida e nunca se arredaram dele! Quis arrebatar Helena; espreitei-a noite e dia. Não a via nunca; a própria casa rara vez tinha uma porta ou janela aberta. Havia ali o recato e o mistério (ASSIS, 2006b, p. 375).

Além de querer raptar a filha, Salvador já havia primeiramente raptado Ângela, com quem fugira romanticamente ao desejo contrário do pai dele, que insistia na separação do casal. É importante frisar que a ideia do duplo rapto (apontado na voz do Padre Melchior) não passou despercebida ao romancista brasileiro, que colheu certamente o tema não só em Homero, mas também na tradição mitopoética posterior,

\footnotetext{
${ }^{4}$ Embora não caiba, nos objetivos deste artigo, o desenvolvimento da tragédia que paralelamente à de Helena assola a vida de seu pai, Salvador, gostaríamos de registrar aqui esse fato, assinalando que Machado desenvolveu com grande maestria o tema do trágico a partir das confissões feitas pelo personagem, com cores tão tristes e verossímeis como as observadas na longa confissão feita a Estácio e ao Padre Melchior.
} 
que apresentava multifacetadas lendas em torno da figura da rainha de Esparta:

Pois bem, essa personagem mítica especial, Helena, foi raptada uma primeira vez pelo herói ateniense Teseu, que a conduziu a Afidna, na Ática, e a confiou à sua mãe Etra. Mas quando Teseu e seu amigo inseparável, Pirítoo, desceram ao Hades para raptar Perséfone [...] os Dioscuros atacaram Afidna, levando de volta sua irmã e como cativa a mãe de Teseu, Etra, que [...] foi conduzida para Troia por Helena, quando de seu segundo rapto por Páris (BRANDÃO, 2012, p. 118).

Em relação ao duplo rapto, então, ao mesmo tempo em que se vale desse mesmo fragmento do mito para a composição de sua narrativa, Machado desloca seu sentido original, reorganizando as posições ocupadas pelos personagens de seu romance nos seguintes termos: Ângela, "cuja beleza foi a causa, a um só tempo, da má e boa fortuna" de Helena (ASSIS, 2006b, p. 372), é raptada por Salvador; após um período de relativa felicidade, abandona-o furtivamente para viver uma paixão com o Conselheiro Vale, tentando inclusive enganar a ele e a Helena sobre o destino do verdadeiro pai da menina - que se ausentara do Rio por motivos particulares e urgentes -, dizendo-o morto. Ato contínuo, Salvador, ao retornar à cidade, sabedor desses episódios como testemunha ocular escondida, planeja o rapto de Helena. Como elo comum entre a tradição mítica grega e o seu terceiro romance, Machado utiliza o elemento trágico que circunda personagens e enredos.

\section{Concluindo: de como ser nacional, mesmo com assuntos gregos}

A essa altura do trabalho, uma pergunta se faz pertinente: como explicar o interesse particular de Machado em fazer tantas citações, estabelecer reiteradamente tantos diálogos com os fragmentos da cultura clássica, como faz o autor, não apenas em Helena, mas em toda a sua obra ficcional? A indagação se torna mais pertinente, entretanto, se levarmos em consideração a tendência geral, observada a partir da estética romântica (correspondente ao período em que Machado escreve seus primeiros contos e romances) de desvalorização dos topoi de resgate da Antiguidade Clássica, utilizados majoritariamente pelos escritores 
europeus e americanos, desde o Humanismo até o Arcadismo. Entre outras estratégias dessa estética, estava incluso o engendramento de um processo consciente de silenciamento da mitologia e da história grecoromanas por parte dos literatos. Machado, contudo, escolherá a via contrária a essa tendência, promovendo um "resgate da noção clássica da aemulatio, que o levou a desenvolver a poética da emulação", conforme observou argutamente João Cezar Rocha (2013, p. 11).

Uma resposta qualificada para a questão, acreditamos, está explícita na posição que o próprio escritor adotou, na persona do crítico literário, papel em que foi aclamado (cumpre ressaltar) publicamente por um romancista da envergadura de José de Alencar. Gostaríamos de citar, então, para concluir, dois trechos da crítica machadiana que explicam, a nosso ver, a relação de proximidade que Machado estabeleceu como ficcionista com o amplo legado deixado lato sensu pelos autores gregos e romanos, herança de um sistema literário com o qual dialoga o cânone ocidental. Ambos se encontram no texto intitulado "Notícia da atual literatura brasileira", também conhecido como "Instinto de nacionalidade". Nele, defende Machado que nacionalismo não deve ser confundido com localismo, sobretudo no caso de países jovens com uma "literatura nascente", como era o Brasil de seu tempo, expressando-se nesses termos:

Não há dúvida que uma literatura, sobretudo uma literatura nascente, deve principalmente alimentar-se dos assuntos que lhe oferece a sua região; mas não estabeleçamos doutrinas tão absolutas que a empobreçam. O que se deve exigir do escritor antes de tudo, é certo sentimento íntimo, que o torne homem de seu tempo e de seu país, ainda que trate de assuntos remotos no tempo e no espaço. Um notável crítico da França, analisando há tempos um escritor escocês, Masson, com muito acerto dizia que do mesmo modo que se podia ser bretão sem falar sempre de tojo, assim Masson era bem escocês, sem dizer palavra de cardo, e explicava o dito acrescentando que havia nele um scotticismo interior, diverso e melhor do que se fora apenas superficial (ASSIS, 2006a, p. 804, grifos nossos, exceto em scotticismo).

Da teoria à práxis, os nortes da advertência do Machado crítico literário são executados pela pena do Machado romancista/contista. O primeiro defende que todo escritor nacional deve gozar de liberdade 
para falar de "assuntos remotos no tempo e no espaço", sem que incorra no problema de ser visto como "menos brasileiro" se comparado a determinados autores da época que priorizavam temáticas ligadas à chamada "cor local", como o tema do indianismo, por exemplo. De fato, é o que buscará exercer o segundo com a pena em punho. Na perspectiva da ficção machadiana, portanto, Grécia e Roma, tão afastadas no tempo e no espaço (e que lhe chegam às mãos por meio de uma transmissão irregular, em que a tradução para as línguas modernas é a via primária de recepção), se fazem próximas, isto é, legíveis, por meio das estratégias narrativas de composição do enredo e, sobretudo, da caracterização dos personagens, baseadas na ressignificação desses textos produzidos na Antiguidade. Seja por meio da estilização - como acontece nos mitos presentes em Helena aqui analisados -, seja por meio da paródia, as relações dialógicas que Machado estabelece com os mitos gregos e romanos revitalizam os clássicos antigos e, mantidas as regras de funcionamento dessa poética, fazem surgir o clássico moderno. Essa noção ampla de uma literatura universal, em que a reescrita de determinados temas e situações perpassa o próprio fazer literário em si, era bastante clara para Machado, que já possuía, aos 34 anos de idade, uma visão bastante acurada de uma questão fulcral para a arte literária brasileira (não apenas de ontem, mas também de hoje):

Cada tempo tem o seu estilo. Mas estudar-lhes as formas mais apuradas da linguagem, desentranhar deles mil riquezas, que, à força de velhas se fazem novas, - não me parece que se deva desprezar. Nem tudo tinham os antigos, nem tudo têm os modernos; com haveres de uns e outros é que se enriquece o pecúlio comum (ASSIS, 2006a, p. 809).

Se pensarmos o êxito que o escritor terá ao longo de uma vida inteira dedicada às Letras brasileiras, em que jamais abandonará o diálogo com Grécia e Roma (para não falar em outras matrizes antigas, como a judaico-cristã, por meio das releituras que operará da Bíblia), como demonstra a sua vasta produção literária, concluímos que, desde os primeiros escritos, Machado soube reconhecer o justo valor dos autores da Antiguidade Clássica para o enriquecimento do "pecúlio comum". Helena, não só pelo nome, mas também por isso, é um dos exemplos mais claros do amadurecimento de um processo antropofágico segundo o qual Machado devorou com prazer outros clássicos que avidamente leu, estilizou, subverteu e reescreveu. 


\section{Agradecimentos}

À FAPEMIG, pelo financiamento do Projeto "Reminiscências da cultura clássica em Helena, de Machado de Assis" (PROBIC/UFV/DLA, 20142015), que permitiu a realização do presente trabalho.

À Professora Neiva Ferreira Pinto, sem cujos estímulos esta pesquisa não teria tomado a dimensão que tomou.

\section{Referências}

ASSIS, Joaquim Maria Machado de. Notícia da atual literatura brasileira - Instinto de nacionalidade. In: . Obra completa. Rio de Janeiro: Nova Aguilar, 2006a. v. 3: Poesia, crônica, crítica, miscelânea e epistolário, p. 803-809.

ASSIS, Joaquim Maria Machado de. Obra completa. Rio de Janeiro: Nova Aguilar, 2006b. v. 1: Romances.

BAKHTIN, Mikhail. O discurso em Dostoiévski. In: Problemas da poética de Dostoievski. Rio de Janeiro: Forense Universitária, 2002. p. 157-238.

BRANDÃO, Junito de Souza. Mitologia grega. 24. ed. Petrópolis: Vozes, 2012. v. 1.

GRIMAL, Pierre. Dicionário da mitologia grega e romana. 5. ed. Rio de Janeiro: Bertrand Brasil, 2005.

HOMERO. Ilíada. Tradução de Manoel Odorico Mendes. Edição e revisão de Teotonio Simões. [S.1.]: Ebooks Brasil, 2009a. E-book. Digitalizado e editado a partir do v. XXI dos Clássicos Jackson, de 1950; da edição de 1874 da Typographia Guttemberg; do exemplar da Harvard College Library, e da edição disponibilizada na web pelo grupo Quatro Contra Troia. Disponível em: $<$ http://www.ebooksbrasil.org/adobeebook/ iliadap.pdf $>$. Acesso em: 4 abr. 2016.

HOMERO. Odisseia. Tradução de Manoel Odorico Mendes. Edição e revisão de Teotonio Simões. [S.1.]: Ebooks Brasil, 2009b. E-book. Digitalizado e editado a partir da 3. ed. da Biblioteca Clássica, da Atena Editora. Disponível em: <http://www.ebooksbrasil.org/adobeebook/ odisseiap.pdf $>$. Acesso em: 4 abr. 2016. 
MARTINS, Edson Ferreira. Afrodite nos trópicos: a reescrita da cultura clássica no romance $A$ mão e a luva, de Machado de Assis. Rónai: Revista de Estudos Clássicos e Tradutórios, Juiz de Fora, v. 3, n. 2, p. 37-62, 2015. ROCHA, João Cezar de Castro. Machado de Assis: por uma poética da emulação. Rio de Janeiro: Civilização Brasileira, 2013.

VIRGÍLIO. Eneida. Tradução de Odorico Mendes. Cotia, SP: Ateliê Editorial; Campinas, SP: Editora da UNICAMP, 2005. 